\title{
A Dynamic Magnetic Resonance Imaging Study of Changes in Severity of Cervical Spinal Stenosis in Flexion and Extension
}

\author{
Yookyung Lee, MD, Seung Yeun Kim, MD, Keewon Kim, MD, PhD \\ Department of Rehabilitation Medicine, Seoul National University Hospital, \\ Seoul National University College of Medicine, Seoul, Korea
}

\begin{abstract}
Objective To evaluate changes in the severity of cervical spinal stenosis (CSS) in flexion and extension and determine whether the rate of change with motion varied with severity.

Methods The study included 92 symptomatic patients with a mean age of $57.80 \pm 10.41$, who underwent cervical spine dynamic magnetic resonance imaging. The severity of stenosis was evaluated using a semi-quantitative CSS score, ranging from 0 (no spinal stenosis) to 18 (severe stenosis). Radiological evaluation included flexion, neutral, and extension measurements, as determined by the $\mathrm{C} 2-\mathrm{C} 7 \mathrm{Cobb}$ angle. The severity of stenosis was represented by the total CSS score. The total CSS score in flexion, neutral, and extension positions was compared using repeated measures one-way analysis of variance. The change rate of stenosis per angle motion (CRSPAM) was defined as change in total CSS score divided by change in Cobb angle. The correlation of CRSPAM with severity of stenosis, represented by total CSS score in neutral position, was evaluated using Pearson correlation analysis.

Results The total CSS score was significantly higher in extension (6.04 \pm 2.68$)$ than in neutral position (5.25 \pm 2.47$)$ $(\mathrm{p}<0.001)$, and significantly higher in neutral than in flexion position $(4.40 \pm 2.45)(\mathrm{p}<0.001)$. The CRSPAM was significantly and positively correlated with total CSS score in neutral position in the flexion-extension range $(\mathrm{r}=0.22$, $\mathrm{p}=0.04)$ and flexion-neutral range $(\mathrm{r}=0.27, \mathrm{p}=0.01)$.

Conclusion In symptomatic CSS patients, the radiological severity of stenosis increases with extension and decreases with flexion. In patients with CSS, the rate of variation in spinal stenosis increases with increased severity.
\end{abstract}

Keywords Spinal stenosis, Cervical vertebrae, Magnetic resonance imaging, Cervical spondylotic myelopathy, Dynamic MRI

Received July 14, 2017; Accepted September 28, 2017

Corresponding author: Keewon Kim

Department of Rehabilitation Medicine, Seoul National University Hospital, Seoul National University College of Medicine, 101 Daehak-ro, Jongno-gu, Seoul 03080, Korea. Tel: +82-2-2072-2619, Fax: +82-2-764-7473, E-mail: keewonkimm.d@gmail.com

ORCID: Yookyung Lee (http://orcid.org/0000-0003-4282-9848); Seung Yeun Kim (http://orcid.org/0000-0002-0994-8055); Keewon Kim (http://orcid. org/0000-0001-6597-578X).

@ This is an open-access article distributed under the terms of the Creative Commons Attribution Non-Commercial License (http://creativecommons.org/ licenses/by-nc/4.0) which permits unrestricted noncommercial use, distribution, and reproduction in any medium, provided the original work is properly cited. Copyright $\odot 2018$ by Korean Academy of Rehabilitation Medicine 


\section{INTRODUCTION}

Cervical spondylotic myelopathy (CSM) is attributed to compressive forces acting on the spine and spinal cord [1]. Cervical spinal stenosis (CSS) and dynamic changes in the spinal canal space in cervical motion are significant factors contributing to the development of CSM [1-3]. Studies using cervical spine dynamic magnetic resonance imaging (MRI) revealed increased stenosis in extension and flexion, supporting the role of dynamic factors in the development of CSM [4-6].

However, previous studies have been inconsistent on whether increased CSS is observed in both flexion and extension. While multiple studies reported increased CSS in extension [4-7], a recent study reported anterior migration of the nucleus pulposus with cervical extension [8], suggesting that cervical extension may play a role in the reversal of disc prolapse, an important factor in CSS. Several studies have shown increased spinal stenosis in flexion [4-6]; however, the detection rate has been consistently lower than in extension, and one study showed a tendency for decompression of the cervical spine in flexion [9].

Therefore, due to conflicting results, the primary aim of this study was to determine whether CSS increased and/ or decreased in flexion and/or extension. The secondary aim of this study was to investigate whether changes per angle motion in CSS differed according to the severity of stenosis.

\section{MATERIALS AND METHODS}

The medical records and imaging studies of 176 consecutive symptomatic patients who underwent cervical spine dynamic MRI from May 2012 to April 2014 were reviewed retrospectively. Patients underwent cervical spine dynamic MRI when cervical radiculopathy or myelopathy was clinically suspected but the correlation with neutral position cervical spine MRI findings was not entirely clear, or when patient's history and X-ray findings suggested cervical spine instability.

Patients aged $>30$ years with symptoms of cervical radiculopathy or CSM were included. The exclusion criteria were: (1) no evidence of CSS on MRI, (2) presence of any comorbidity significantly affecting general function, and (3) non-spondylotic myelopathy (i.e., traumatic or meta- static).

This study was approved by the Institutional Review Board of Seoul National University Hospital (IRB No. 1611-040-805).

\section{Participants}

A total of 92 patients with a mean age of $57.80 \pm 10.41$ years, were included in the study (Table 1). Most patients (84.78\%) manifested mild symptoms of Nurick grade 0 to 1. Upper extremity sensory symptoms $(77.17 \%)$ were the most frequent source of complaint, with median symptom duration of 4 months.

Intervertebral disc degeneration was assessed [10], and the highest Pfirrmann grade between $\mathrm{C} 2 / 3$ and $\mathrm{C} 7 / \mathrm{T} 1$ segments was recorded. Cervical intervertebral disc levels with the most severe CSS were defined as stenosis levels and recorded. Multiple levels were recorded if cervical canal stenosis of the same severity was found at multiple levels. The most severe level of stenosis was found at the $\mathrm{C} 5 / 6$ vertebral segment ( $70.33 \%$ ), followed by $\mathrm{C} 4 / 5$ (46.15\%).

\section{Patient positioning for MRI}

All patients were examined with cervical dynamic MRI $(1.5 \mathrm{~T}$ or $3.0 \mathrm{~T})$ in the supine position. Dynamic MRI was performed by positioning cushions under the posterior neck for extension and posterior head for flexion, as tolerated. T1- and T2-weighted sagittal images and T2weighted axial images were acquired in the neutral position, and sagittal T2-weighted images were acquired in flexion and extension positions.

An illustrative case of cervical dynamic MRI is presented in Fig. 1.

\section{Parameters}

The total CSS score was defined as the sum of CSS grades [11] from the vertebral segments $\mathrm{C} 2 / 3$ to $\mathrm{C} 7 / \mathrm{T} 1$. The CSS grade was categorized as follows: grade 0 , no spinal stenosis; grade 1 , more than $50 \%$ of subarachnoid space obliterated without signs of spinal cord deformity; grade 2 , cord deformity without signal change on the spinal cord; and grade 3, increased signal intensity on the spinal cord in T2-weighted image. Total CSS score was determined in flexion, neutral, and extension positions by a single observer, and was used as a measure of spinal stenosis. 
Table 1. Patients' demographics

\begin{tabular}{|c|c|}
\hline Characteristic & Value \\
\hline Age (yr) & $57.80 \pm 10.41$ \\
\hline Sex (male:female) & $53: 39$ \\
\hline Trauma history & $10(10.87)$ \\
\hline \multicolumn{2}{|l|}{ Nurick grade } \\
\hline 0 & $22(23.91)$ \\
\hline 1 & $56(60.87)$ \\
\hline 2 & $11(11.96)$ \\
\hline 3 & $3(3.26)$ \\
\hline \multicolumn{2}{|l|}{ Symptoms } \\
\hline Upper extremity motor & $33(35.87)$ \\
\hline Lower extremity motor & $18(19.57)$ \\
\hline Upper extremity sensory & $71(77.17)$ \\
\hline Lower extremity sensory & $35(38.04)$ \\
\hline Bladder & $4(4.35)$ \\
\hline Symptom duration (mo) & $4(0.25-360)$ \\
\hline \multicolumn{2}{|l|}{ Comorbidities } \\
\hline $\mathrm{DM}$ & $16(17.39)$ \\
\hline Hypertension & $22(23.91)$ \\
\hline Dyslipidemia & $1(1.09)$ \\
\hline CLD & $3(3.26)$ \\
\hline \multicolumn{2}{|l|}{ Spinal surgery history } \\
\hline Cervical & $3(3.26)$ \\
\hline Lumbar & $5(5.43)$ \\
\hline \multicolumn{2}{|l|}{ Pfirrmann grade } \\
\hline 3 & $41(44.57)$ \\
\hline 4 & $43(46.74)$ \\
\hline 5 & $8(8.70)$ \\
\hline \multicolumn{2}{|l|}{ Stenosis levels } \\
\hline $\mathrm{C} 2 / 3$ & $3(3.30)$ \\
\hline $\mathrm{C} 3 / 4$ & $39(42.86)$ \\
\hline $\mathrm{C} 4 / 5$ & $42(46.15)$ \\
\hline $\mathrm{C} 5 / 6$ & $64(70.33)$ \\
\hline $\mathrm{C} 6 / 7$ & $37(40.66)$ \\
\hline $\mathrm{C} 7 / \mathrm{T} 1$ & $1(1.10)$ \\
\hline \multicolumn{2}{|l|}{ Total CSS grade } \\
\hline Flexion & $4.40 \pm 2.45$ \\
\hline Neutral & $5.25 \pm 2.47$ \\
\hline Extension & $6.04 \pm 2.68$ \\
\hline
\end{tabular}

Cervical spine Cobb angle (C2-C7) [12] was measured in flexion, neutral, and extension positions.

The change rate in stenosis per angle motion (CRSPAM) was defined as change in total CSS score divided by
Table 1. Continued

\begin{tabular}{|cc}
\hline \multicolumn{1}{c}{ Characteristic } & \multicolumn{1}{c}{ Value } \\
\hline C2-C7 Cobb angle $\left(^{\circ}\right)$ & \\
\hline Flexion & $7.54 \pm 11.30$ \\
\hline Neutral & $-6.28 \pm 11.62$ \\
\hline Extension & $-19.75 \pm 10.75$ \\
\hline
\end{tabular}

Values are presented as mean \pm standard deviation or number (\%) or median (range).

DM, diabetes mellitus; CLD, chronic liver disease; CSS, cervical spinal stenosis.

change in Cobb angle. The CRSPAM varied with the severity of spinal stenosis, and was determined for flexionextension, flexion-neutral, and neutral-extension ranges.

\section{Statistics}

Statistical analysis was performed using SAS version 9.4 (SAS Institute Inc., Cary, NC, USA). To compare the degree of CSS in flexion, neutral, and extension positions between individual patients, the total CSS score in each position was compared using one-way repeated measures analysis of variance.

To examine the rates of CSS variation in relation to the severity of stenosis, the CRSPAM was determined in the flexion-extension, flexion-neutral, and neutral-extension ranges, and its relationship to total CSS score in neutral position was evaluated using Pearson correlation analysis.

\section{RESULTS}

Total CSS scores in flexion, neutral, and extension positions were $4.40 \pm 2.45,5.25 \pm 2.47$, and $6.04 \pm 2.68$, respectively. Total CSS score was significantly higher in extension than in neutral $(\mathrm{p}<0.001)$ and significantly higher in neutral than in flexion positions $(\mathrm{p}<0.001)$ (Fig. 2).

CRSPAM showed a weak positive correlation $(\mathrm{r}=0.22)$ with total CSS score in neutral position in the flexion and extension range $(\mathrm{p}=0.04)$ (Fig. 3A). CRSPAM also showed a weak positive correlation $(\mathrm{r}=0.27)$ with total CSS score in neutral position in the flexion and neutral range $(\mathrm{p}=0.01)$ (Fig. 3B). However, such correlation was not detected in the neutral and extension ranges (Fig. 3C). 

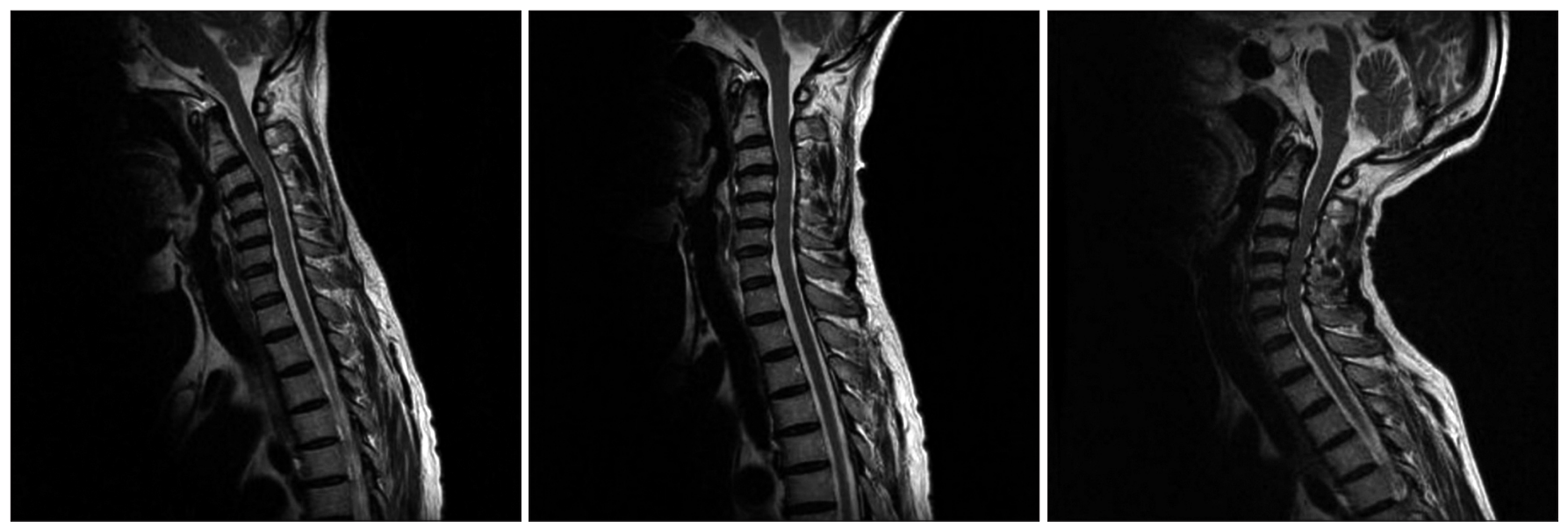

Fig. 1. Illustrative case of cervical dynamic magnetic resonance imaging in left-to-right flexion, neutral, and extension positions.

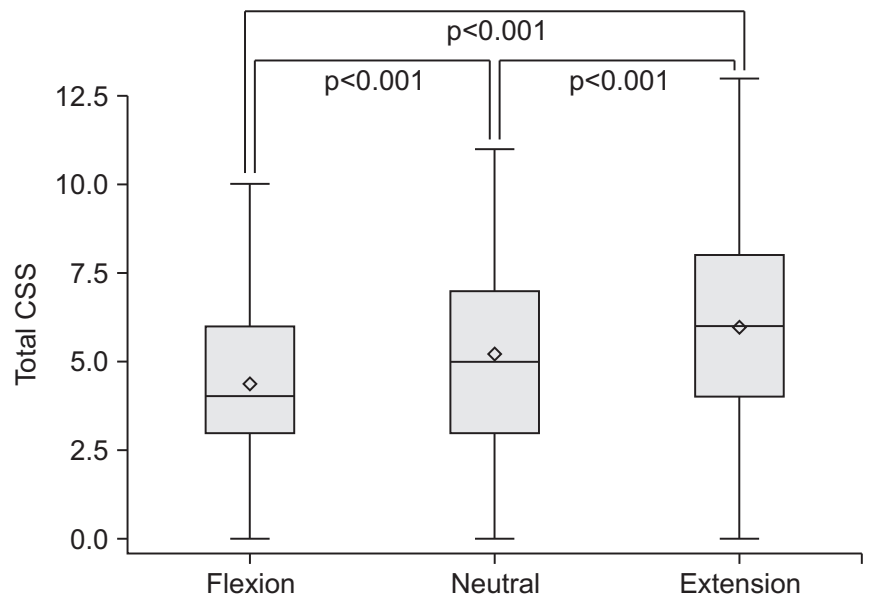

Fig. 2. Total cervical spinal stenosis (CSS) score in flexion, neutral, and extension positions.

\section{DISCUSSION}

This study demonstrated that in symptomatic patients with CSS, extension was associated with narrowing of the cervical spinal canal and flexion, with decreased stenosis. The severity of CSS increased with progression from flexion to neutral and extension positions. With extension, the rate of variation in stenosis increased with increased CSS severity (Fig. 3A).

This study reinforced the results of a previous report of increased CSS in extension and a relative decrease in stenosis in flexion [9]. However, the results of previous studies varied, with a few reporting increased stenosis in both flexion and extension [4-7], while others suggested decreased disc prolapse in extension $[8,13]$. The inconsistent results may be attributed to differences in participant characteristics. The study reporting anterior migration of the nucleus pulposus in extension was conducted on healthy volunteers [8]. With disc degeneration, the nucleus pulposus condenses and the annulus is weakened and stiffened [14], leading to difficulties in anterior migration of disc material. Furthermore, neck extension may lead to posterior spinal cord compression due to ligamentum flavum hypertrophy [15], which is not common in healthy volunteers with minimal cervical spondylosis.

In contrast to previous studies reporting the association of flexion with increased spinal stenosis, our results showed that spinal stenosis was decreased in flexion. This discrepancy may have been due to differences in the method of spinal stenosis evaluation. This study used total CSS score to measure spinal stenosis. Since CSS grading at each vertebral segment was totaled, small changes may have been accentuated or significant changes at a single level may have been diluted. In most cases, a tendency for decreased spinal stenosis in flexion was seen in all vertebral segments (illustrative case, Fig. 1). However, cases of instability evident at a single level and aggravated spinal stenosis in flexion were not adequately appreciated in our study. With cervical flexion, the ligamentum flavum becomes relatively thinner than in extension [16], leading to posterior decompression. However, the spinal cord is also stretched and compressed against the posterior longitudinal ligament and vertebral body [17]. Therefore, despite the decrease in total CSS score in flexion, the 

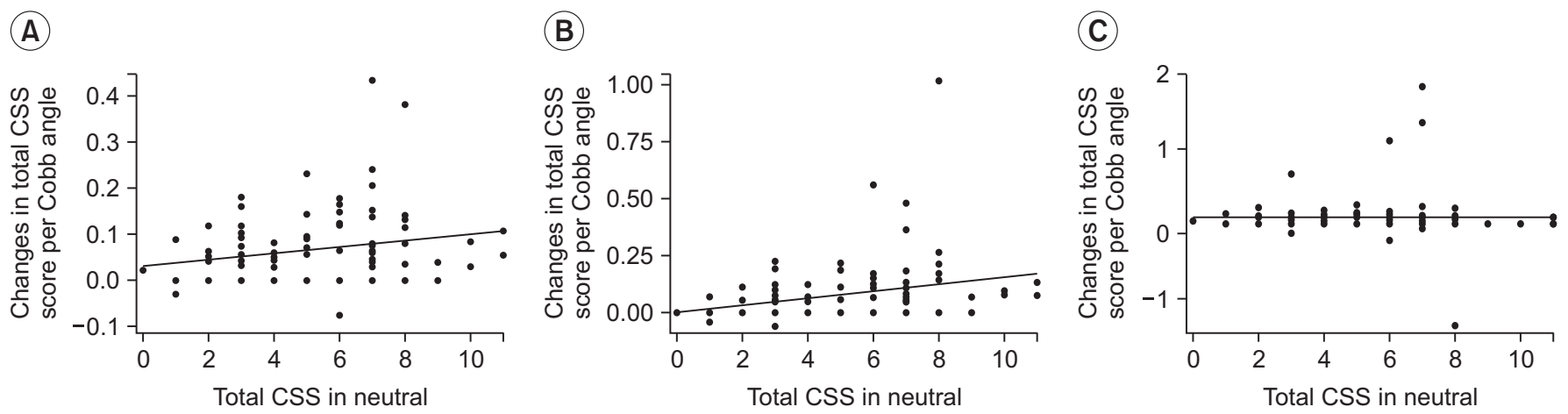

Fig. 3. Change rate in stenosis per angle motion in flexion and extension (A), flexion and neutral (B), and neutral and extension (C) ranges in relation to total cervical spinal stenosis (CSS) score in neutral position.

spinal cord may be injured during motion, warranting caution in translating results into clinical practice. Furthermore, increased stenosis at the most stenotic level is clinically more important than the total CSS score.

Interestingly, our study results showed that increased severity of spinal stenosis markedly elevated the rate of change in spinal stenosis in the flexion-neutral range (Fig. 3B), but not in the neutral-extension range (Fig. 3C). A possible explanation is the 'ceiling effect' of CSS grading. Patients with more severe stenosis may have higher changes in the flexion-neutral range because of lack of free space, without significant changes in the neutralextension range because of the ceiling effect. However, in such a case, patients with mild stenosis show significant changes in the neutral-extension range, which was not observed in our study. Studies have reported differences in spinal kinematics according to sagittal alignment and disc degeneration $[18,19]$. Our study findings may have been affected by differences in kinematics. Further studies using quantitative kinematic analysis are needed for verification.

Our study has clinical implications. A cervical extension maneuver is still widely used to treat cervical spinal pain [20]. Our findings indicate that caution is needed in extension, especially in patients with severe CSS. Clinically, it is still uncertain whether extension should be limited, because it is established that disc degeneration and ensuing kyphotic posture are delayed with extension exercises $[21,22]$. Since the rate of increase in CSS was greater in patients with a higher severity of stenosis, patients with severe stenosis may need to restrict cervical motion. Our findings of increased stenosis in extension and a relative decrease in flexion may explain the kyphotic posture in CSM patients [23], a compensatory action to degenerative changes, although the association was not investigated.

This study has several limitations. First, it was a retrospectively study. Second, MRI was performed with patients in the supine position. Results may differ in the upright position. Third, semi-quantitative evaluation was conducted using a CSS score. Semi-quantitative analyses are less reliable than quantitative analysis. In the presence of cord signal changes, CSS was graded as 3 in all three positions regardless of change in canal space. Therefore, in the presence of cord signal changes, narrowing of the spinal canal was not reflected in the CSS score. Total CSS score was used in our study to represent the total stenosis severity score. The contribution of spine motion to canal stenosis according to the spine level was not evaluated due to inherent limits of the CSS grading, which was not sensitive enough to capture delicate changes in canal stenosis. Due to limitations associated with time and cost, the dynamic cervical spine MRI protocol at our hospital does not include axial images in all the three positions and stenosis was only evaluated in the sagittal plane, and not in the axial plane. Finally, whether anterior or posterior compression contributed to spinal stenosis was not evaluated.

In conclusion, cervical extension is associated with increased radiological spinal stenosis and flexion with decreased stenosis in symptomatic patients with CSS. The rate of increase in spinal stenosis under extension is associated with the severity of spinal stenosis. Therefore, caution is needed in performing cervical extension exercises in CSS patients. Further studies using quantitative 
kinematics with MRI in the upright position are needed to better elucidate mechanisms and factors underlying the dynamic changes in spinal stenosis.

\section{CONFLICT OF INTEREST}

No potential conflict of interest relevant to this article was reported.

\section{ACKNOWLEDGMENTS}

This research was supported by the Bio \& Medical Technology Development Program of the National Research Foundation (NRF) funded by the Korean government (MEST) (No. NRF-2016M3A9F1941984).

\section{REFERENCES}

1. Baptiste DC, Fehlings MG. Pathophysiology of cervical myelopathy. Spine J 2006;6(6 Suppl):190S-7S.

2. Lebl DR, Bono CM. Update on the diagnosis and management of cervical spondylotic myelopathy. J Am Acad Orthop Surg 2015;23:648-60.

3. Toledano M, Bartleson JD. Cervical spondylotic myelopathy. Neurol Clin 2013;31:287-305.

4. Muhle C, Weinert D, Falliner A, Wiskirchen J, Metzner J, Baumer M, et al. Dynamic changes of the spinal canal in patients with cervical spondylosis at flexion and extension using magnetic resonance imaging. Invest Radiol 1998;33:444-9.

5. Chen CJ, Hsu HL, Niu CC, Chen TY, Chen MC, Tseng YC, et al. Cervical degenerative disease at flexionextension MR imaging: prediction criteria. Radiology 2003;227:136-42.

6. Hayashi T, Wang JC, Suzuki A, Takahashi S, Scott TP, Phan K, et al. Risk factors for missed dynamic canal stenosis in the cervical spine. Spine (Phila Pa 1976) 2014;39:812-9.

7. Lao L, Daubs MD, Scott TP, Phan KH, Wang JC. Missed cervical disc bulges diagnosed with kinematic magnetic resonance imaging. Eur Spine J 2014;23:1725-9.

8. Kim YH, Kim SI, Park S, Hong SH, Chung SG. Effects of cervical extension on deformation of intervertebral disk and migration of nucleus pulposus. PM R 2017;9:329-38.

9. Muhle C, Metzner J, Weinert D, Falliner A, Brinkmann
G, Mehdorn MH, et al. Classification system based on kinematic MR imaging in cervical spondylitic myelopathy. AJNR Am J Neuroradiol 1998;19:1763-71.

10. Pfirrmann CW, Metzdorf A, Zanetti M, Hodler J, Boos N. Magnetic resonance classification of lumbar intervertebral disc degeneration. Spine (Phila Pa 1976) 2001;26:1873-8.

11. Kang Y, Lee JW, Koh YH, Hur S, Kim SJ, Chai JW, et al. New MRI grading system for the cervical canal stenosis. AJR Am J Roentgenol 2011;197:W134-40.

12. Ohara A, Miyamoto K, Naganawa T, Matsumoto K, Shimizu K. Reliabilities of and correlations among five standard methods of assessing the sagittal alignment of the cervical spine. Spine (Phila Pa 1976) 2006;31:2585-91.

13. Scannell JP, McGill SM. Disc prolapse: evidence of reversal with repeated extension. Spine (Phila Pa 1976) 2009;34:344-50.

14. Adams MA, Roughley PJ. What is intervertebral disc degeneration, and what causes it? Spine (Phila Pa 1976) 2006;31:2151-61.

15. Tracy JA, Bartleson JD. Cervical spondylotic myelopathy. Neurologist 2010;16:176-87.

16. Sayit E, Daubs MD, Aghdasi B, Montgomery SR, Inoue $\mathrm{H}$, Wang $\mathrm{CJ}$, et al. Dynamic changes of the ligamentum flavum in the cervical spine assessed with kinetic magnetic resonance imaging. Global Spine J 2013;3:69-74.

17. Lebl DR, Hughes A, Cammisa FP Jr, O'Leary PF. Cervical spondylotic myelopathy: pathophysiology, clinical presentation, and treatment. HSS J 2011;7:170-8.

18. Morishita Y, Hida S, Miyazaki M, Hong SW, Zou J, Wei $\mathrm{F}$, et al. The effects of the degenerative changes in the functional spinal unit on the kinematics of the cervical spine. Spine (Phila Pa 1976) 2008;33:E178-82.

19. Miyazaki M, Hymanson HJ, Morishita Y, He W, Zhang $\mathrm{H}, \mathrm{Wu} \mathrm{G}$, et al. Kinematic analysis of the relationship between sagittal alignment and disc degeneration in the cervical spine. Spine (Phila Pa 1976) 2008;33:E8706.

20. Clare HA, Adams R, Maher CG. A systematic review of efficacy of McKenzie therapy for spinal pain. Aust J Physiother 2004;50:209-16.

21. Ball JM, Cagle P, Johnson BE, Lucasey C, Lukert BP. Spinal extension exercises prevent natural progression of kyphosis. Osteoporos Int 2009;20:481-9. 
22. Shedid D, Benzel EC. Cervical spondylosis anatomy: pathophysiology and biomechanics. Neurosurgery 2007;60(1 Supp1 1):S7-13.

23. Machino M, Yukawa $Y$, Imagama S, Ito K, Katayama Y, Matsumoto T, et al. Age-related and degenerative changes in the osseous anatomy, alignment, and range of motion of the cervical spine: a comparative study of radiographic data from 1016 patients with cervical spondylotic myelopathy and 1230 asymptomatic subjects. Spine (Phila Pa 1976) 2016;41:476-82. 